\title{
Examining school-based hygiene facilities: a quantitative assessment in a Ghanaian municipality
}

\author{
Emmanuel Appiah-Brempong ${ }^{1 *}$ D, Muriel J. Harris ${ }^{2}$, Samuel Newton ${ }^{3}$ and Gabriel Gulis ${ }^{4}$
}

\begin{abstract}
Background: The crucial role of adequate water, sanitation and hygiene (WASH) facilities in influencing children's handwashing behaviour is widely reported. Report from UNICEF indicates a dearth of adequate data on WASH facilities in schools, especially in the developing world. This study sought to contribute to building the evidencebase on school hygiene facilities in Ghana. The study further explored for possible associations and differences between key variables within the context of school water, sanitation and hygiene.
\end{abstract}

Methods: Data was collected from 37 junior high schools using an observational checklist. Methods of data analysis included a Scalogram model, Fisher's exact test, and a Student's t-test.

Results: Results of the study showed a facility deficiency in many schools: $33 \%$ of schools had students washing their hands in a shared receptacle (bowl), $24 \%$ had students using a single cotton towel to dry hands after handwashing, and only $16 \%$ of schools had a functional water facility. Furthermore, results of a proportion test indicated that $83 \%$ of schools which had functional water facilities also had functional handwashing stations. On the other hand, only $3 \%$ of schools which had functional water facilities also had a functional handwashing stations. A test of difference in the proportions of the two sets of schools showed a statistically significant difference $(p<0.001)$.

In addition, 40\% of schools which had financial provisions for water supply also had functional handwashing stations. On the other hand, only $7 \%$ of schools which had financial provisions for water supply also had functional handwashing stations. There was a statistically significant difference in the proportions of the two sets of schools $(p=0.02)$.

Conclusion: We conclude that it is essential to have a financial provision for water supply in schools as this can potentially influence the existence of a handwashing station in a school. An intervention by government, educational authorities and civil society organisations towards enabling schools in low resource areas to have a sustainable budgetary allocation for WASH facilities would be timely.

Keywords: School, Water, Hygiene, Functional, Facilities

\section{Background}

Infectious diseases continue to claim many lives especially among children. Though the developed world is not exempted from this phenomenon, the developing world is often hit the hardest. For example, diarrhoeal diseases have been listed as one of four leading causes of early death in all sub-Saharan African countries [1]. In the year 2015, approximately 1400 children lost their

\footnotetext{
* Correspondence: e.brempong@yahoo.com; ebrempong.chs@knust.edu.gh ${ }^{1}$ Department of Health Promotion and Education, Kwame Nkrumah University of Science and Technology (KNUST), Kumasi, Ghana Full list of author information is available at the end of the article
}

lives each day as a result of diarrhoea [2]. Preventing the spread of infectious agents in schools is a good way towards minimizing the infectious disease burden among children. The provision of adequate water, sanitation and hygiene (WASH) facilities in schools is crucial in ensuring the adoption and maintenance of safe sanitation and hygiene practices among school children.

The available evidence suggests that schools with better hygienic conditions tend to have less problems with disease causing organisms [3]. In the light of this, WASH in schools deserves increased attention both at the global and national levels. A laudable expression in

(c) The Author(s). 2018 Open Access This article is distributed under the terms of the Creative Commons Attribution 4.0 International License (http://creativecommons.org/licenses/by/4.0/), which permits unrestricted use, distribution, and 
the UN Sustainable Development Goals (SDGs) is the recognition of WASH in Schools (WinS) in Goals 4 and 6. However, such global expressions ought to be translated into national and local policies and actions in order to improve WinS substantially.

The crucial role of adequate WASH facilities towards influencing children's handwashing behaviour is widely known [4, 5]. A functional handwashing station in a school makes it possible for children to adopt the practice of handwashing with soap (HWWS). In spite of this importance, national monitoring systems for WASH which are intended to report on the availability and state of handwashing facilities in schools is generally weak especially in developing countries. Few developing countries have reliable data on hygiene facilities in schools, of which Ghana is no exception. According to UNICEF, only about half of its programme countries are able to report on WASH facilities in schools [6]. The dearth of reliable data on the functionality of WASH facilities in schools is worrisome, as such data is required for good programme design and management [6].

There is a paucity of studies examining hand hygiene facilities in African schools. In Ghana, Steiner-Asiedu et al. as well as Monney et al. have attempted to describe the available handwashing facilities in a sample of schools $[7,8]$. However, no study was identified to have quantitatively explored the associations or variance between a functional water facility, financial provision for water supply, and existence of a handwashing station. The present study sought to employ a more robust quantitative approach to generate evidence on the existence and functionality of hygiene facilities within a representative sample of basic schools in a Ghanaian municipality. Precisely, we sought to test the following null hypotheses:

1. Ho: With regards to the existence of a functional handwashing station, the proportion of schools having a financial provision for water supply will not differ from the proportion of schools lacking a financial provision for water supply.

2. Ho: With regards to the existence of a functional handwashing station, the proportion of schools having a functional water facility will not differ from the proportion of schools lacking a functional water facility.

\section{Methods}

\section{Approach and design}

The methodological approach adopted for the study was quantitative. A study seeking to objectively assess the existence, proportions and relationships between existing facilities is better approached from a positivist perspective, and hence the choice of a quantitative methodology. A cross-sectional design was employed for this assessment, and so study variables were assessed at only one point in time.

\section{Study population and sample size}

The study population was made up of all public junior high schools within the Ejisu-Juaben Municipal Education Directorate. In all, there were 80 public junior high schools organised within 10 educational circuits. The list of schools was obtained from the Municipal Education Directorate. A representative sample of 37 schools was derived using two complementary formulas by Yamane and the Pennsylvania State University $[9,10]$.

\section{Sampling technique}

In a bid to ensure that each school in all 10 educational circuits had an equal chance of being a part of the study, and in a manner that enhances the external validity of study results, a stratified random sampling technique was employed. With this technique, educational circuits constituted the strata, while schools constituted the sample units. In line with the above technique, a proportionate stratification approach was used [11]. This approach ensured that the sample size (i.e. number of schools required from each educational circuit) of each stratum (i.e. an educational circuit) was proportional to the population size of the stratum being considered [12]. Table 1 shows the estimated number of schools from each educational circuit.

\section{Description of data collection procedures and tools}

Data was collected from March 2016 to July 2016, spanning a period of five calendar months. A checklist adapted from UNICEF and Moore et al. aided the environmental audit of schools in order to obtain first hand data on existing facilities $[6,13]$. A decision on which facilities to target was guided by a WASH in schools monitoring package developed by UNICEF [6]. The observation tool was pretested in a junior high school located in a municipality which is contiguous to the geographic scope of this study (student enrolment, $n=256$ ),

Table 1 School Selection

\begin{tabular}{llll}
\hline ID & $\begin{array}{l}\text { EDUCATIONAL } \\
\text { CIRCUIT }\end{array}$ & $\begin{array}{l}\text { POPULATION SIZE } \\
\text { OF CIRCUIT }\end{array}$ & $\begin{array}{l}\text { ESTIMATED NO. OF } \\
\text { SCHOOLS REQUIRED }\end{array}$ \\
\hline A & Achinakrom & 6 & 3 \\
B & Bomfa & 8 & 4 \\
C & Ejisu & 11 & 5 \\
D & Fumesua & 5 & 2 \\
E & Kubease & 8 & 4 \\
F & Kwaso & 9 & 4 \\
G & New Koforidua & 6 & 3 \\
H & Ofoase & 5 & 2 \\
I & Juaben & 14 & 6 \\
J & Tikrom & 8 & 4 \\
TOTAL & 80 & 37
\end{tabular}

Source: Developed based on a list obtained from the EJM Education Directorate, 2016 
and was subsequently fine-tuned. For instance, after the pretest it became necessary to include an item that enabled the observation of a functional toilet facility within schools. This was essential due to the complementarity of the concepts of hygiene and sanitation. Where required, clarifications on facilities were sought from the head teacher or an authorized representative of the school. The checklist makes use of dichotomous questions and assesses the school environment based on predetermined parameters, including: accessibility and source of water point, existence of handwashing stations, functionality of toilet facility, and accessibility to the toilet facility.

Data was collected by the lead researcher with assistance from trained field enumerators. Field enumerators were given a 3-h training by the lead researcher who has substantial experience in observational studies. All field enumerators were university graduates serving as teaching and research assistants in a public university.

\section{Data analysis}

Descriptive statistical analysis was used in describing the existing facilities for handwashing in schools. For profiling the existing WASH facilities in participating schools, a scalogram model was used. In exploring for possible relationships between key variables, and differences in proportions of variables, statistical tests used were the Student's $t$-test, Fisher's exact test, and a two-sample proportion test. Data was analyzed using STATA version 14.0 (STATA Corp., College Station, Texas).

\section{Ethical considerations}

The research protocol was reviewed and subsequently granted clearance by the Committee on Human Research, Publications and Ethics (CHRPE) of the Kwame Nkrumah University of Science and Technology, Ghana. In addition, an approval to conduct the research was obtained from the Ejisu-Juaben Municipal Education Directorate of the Ghana Education Service, a regulatory body of all basic schools within the study area.

\section{Results}

\section{Characteristics of schools, and distribution of facilities}

Observations of hygiene facilities occurred in all 37 schools. All participating schools were public, and none was a single-sex school. The mean student enrolment was $153(\mathrm{SD}=81.9)$. The minimum student enrolment was 46 while the maximum was 394. Table 2 presents summary statistics on the proportions of schools with specific facilities.

Soap was the most common item observed in participating schools. Sixty-eight percent $(68 \%)$ of schools had soap available for use. Out of the number of schools having soap $(n=25), 4 \%$ had a liquid soap, while the remaining schools had a solid soap (96\%). Sixteen percent $(16 \%)$ of schools had a functional water facility within its compound. Most of these facilities were boreholes (in $83 \%$ of schools), and $17 \%$ had a stand-pipe (tap-water).

Of the 37 participating schools, $6(16 \%)$ had a functional handwashing station. The average number of functional handwashing stations was $2(\mathrm{SD}=0.98)$. Only $19 \%$ of schools had a handwashing facility attached to a toilet facility. Also, $23 \%$ of schools had a separate handwashing station for teachers. Also, 33\% of schools had students washing their hands in a shared receptacle (bowl), 24\% had students using a single cotton towel to dry hands after handwashing, and none of the schools had a paper towel displayed for hand drying.

With regards to functional toilet facilities, $56 \%$ had this within the school compound. The types of toilet facility observed were the WC (6\%), VIP (6\%) and the Simple Pit Latrine (88\%). The mean number of cubicles within a toilet facility was $4.9(\mathrm{SD}=2.6)$. All schools had a separate section of the toilet facility for males and females. Also, $75 \%$ of schools had a separate section designated for teachers.

A financial provision for running handwashing stations reportedly existed in $27 \%$ of schools. Two main streams of revenue for sustaining a WinS were identified. These were the "capitation grant" from central government, and the internally generated funds (IGF). Most schools (94\%) depend largely on the IGF for maintaining WASH facilities. Inflows to the IGF were identified to be from the sporadic donations from the Parents and Teachers Association (PTA), as well as the weekly fundraising sessions held during religious activities in schools. With regards to the adequacy of funds for maintaining WASH facilities, all schools $(n=21)$ described their financial resources as inadequate.

\section{A profile of facilities in schools}

The observed handwashing (HW) and related facilities in participating schools are profiled with the aid of a scalogram model presented as Table 3 . With reference to Table 3, columns 1 and 2 present a list of all sampled schools with their respective student enrolment figures. The second row presents the facilities assessed in this study. Corresponding to the facilities are codes indicating whether or not a particular facility exists in a particular school. Thus, code "1" means a facility exist, while code " 0 " means otherwise. At the base of the matrix are the corresponding weights of each of the facilities calculated by dividing the assumed centrality by the total number of facilities. Columns 11 and 12 shows the total number of facilities in each school as well as the centrality indices. Centrality index is a sum of the weights of all facilities which exist in a particular school. 
Table 2 Proportion of Schools with Specific Facilities

\begin{tabular}{llll}
\hline S/N & Item & Number of Schools & Percentage (\%) \\
\hline A & Functional $^{\text {b }}$ water point/facility & 6 & 16 \\
B & Functional $^{\text {b }}$ water reservoir & 4 & 11 \\
C & Soap & 25 & 68 \\
D & Tap bucket (veronica bucket) & 13 & 36 \\
E & Shared/communal a HW receptacle & 12 & 33 \\
F & Receptacle (for waste water) & 11 & 31 \\
G & Paper/tissue towel & 0 & 0 \\
H & Shared cotton towel/napkin & 9 & 24 \\
I & Functional handwashing station & 6 & 16 \\
J & Functional toilet facility & 21 & 56 \\
Financial Provision for HW Facilities & Financial Provision for facilities & 10 & 27 \\
K & Source of funds & & 6 \\
L & o Capitation grant & 1 & 94
\end{tabular}

Source: Field Survey, $2017{ }^{\mathrm{a} H W}$-Handwashing ${ }^{\mathrm{b}}$ Facility was usable on the day of observation

From Table 3, school with identifier 0037 had the highest centrality index $(\mathrm{CI}=84.80)$ by having nearly all observed facilities in school. On the other hand, schools with the lowest CI include 0002, 0009, 0012, 0013, 0016, and 0019 (all with a $\mathrm{CI}=0.0$ ), depicting the nonexistence of at least one of the facilities for which observations were made.

\section{Differences in proportions of facilities in schools}

Differences in proportions, and differences in means of group variables were explored and the results are presented in Table 4. Results of an independent samples $t$-test shows a statistically significant difference in mean student enrolment of schools which had a functional toilet facility and schools which did not a functional toilet facility $[t(35)$ $=-2.06, p=.04 \mathrm{]}$ : Schools which had a functional toilet facility were observed to have a higher mean enrolment fig. $[M=177(S D=76)]$, when compared with schools which did not have this facility [(M=123(SD = 82)]. On the contrary, there was no statistically significant difference in the mean student enrolment of schools where a functional handwashing station existed and schools where it did not exist $[t(35)=-0.38, p=.69]$.

To determine the possible associations existing between explanatory variables (i.e. functional water facility, functional toilet facility, existence of a financial provision for water supply), and a response variable 'functional handwashing station', results of a Fisher's exact test (twotailed) indicated a statistically significant association between 'functional handwashing station' and 'functional water facility' ( $p<.001$; Fisher's exact), and also 'financial provision for water supply' ( $p=.03$; Fisher's exact), but not 'functional toilet facility' ( $p=.16$; Fisher's exact).

In a bid to further examine the differences in proportions of each of the pairs of categories of explanatory variables (where a statistically significant $p$-value was generated), results of a two-sample proportion test (twotailed) indicated that $83 \%$ of schools which had functional water facilities also had functional handwashing stations. On the other hand, only 3\% of schools which had functional water facilities also had functional handwashing stations. A test of difference in the proportions of the two sets of schools showed a statistically significant difference $(z=-4.87, p<0.001)$.

In addition, $40 \%$ of schools which had financial provisions for water supply also had functional handwashing stations. On the other hand, only $7 \%$ of schools which had financial provisions for water supply also had functional handwashing stations. There was a statistically significant difference in the proportions of the two sets of schools $(z=-2.38, p=0.02)$.

\section{Discussion}

\section{Distribution of facilities in schools}

The study has shown that most schools had soap available to students (68\%). Also, few schools had a functional water facility (16\%). Similarly, few schools had a functional handwashing station (16\%), which leaves much to be desired, considering the fact that $21 \%$ of schools in the developing world have handwashing facilities [14]. Furthermore, a large number of students wash their hands in a shared receptacle and also dry their hands with a common towel. More so, only half of the 
Table 3 A Scalogram Model on Schools and Functional Facilities

\begin{tabular}{|c|c|c|c|c|c|c|c|c|c|c|c|}
\hline \multirow{2}{*}{$\begin{array}{l}\text { School } \\
\text { Identifier }\end{array}$} & \multirow{2}{*}{$\begin{array}{l}\text { Student } \\
\text { Enrolment } \\
M(S D)=153(81.9)\end{array}$} & \multicolumn{8}{|c|}{ Existing Functional Facilities } & \multirow{2}{*}{$\begin{array}{l}\text { Total no. of } \\
\text { facilities }\end{array}$} & \multirow{2}{*}{$\begin{array}{l}\text { Centrality } \\
\text { Indices }\end{array}$} \\
\hline & & $\begin{array}{l}\text { Water } \\
\text { Point }\end{array}$ & $\begin{array}{l}\text { Hand-washing } \\
\text { Station }\end{array}$ & $\begin{array}{l}\text { Water } \\
\text { Reservoir }\end{array}$ & $\begin{array}{l}\text { Tap } \\
\text { Bucket }\end{array}$ & Soap & $\begin{array}{l}\text { Receptacle } \\
\text { (waste water) }\end{array}$ & Toilet & $\begin{array}{l}\text { Budget-Water } \\
\text { Supply }\end{array}$ & & \\
\hline 0037 & 309 & 1 & 1 & 1 & 1 & 1 & 0 & 1 & 1 & 7 & 84.8 \\
\hline 0027 & 198 & 1 & 1 & 1 & 1 & 1 & 0 & 1 & 0 & 6 & 74.8 \\
\hline 0031 & 84 & 1 & 1 & 0 & 1 & 1 & 1 & 1 & 1 & 7 & 68.8 \\
\hline 0023 & 178 & 1 & 1 & 0 & 1 & 1 & 0 & 1 & 1 & 6 & 59.8 \\
\hline 0036 & 177 & 0 & 1 & 0 & 1 & 1 & 1 & 1 & 1 & 6 & 52.1 \\
\hline 0028 & 201 & 0 & 0 & 1 & 0 & 1 & 1 & 1 & 0 & 4 & 42.7 \\
\hline 0003 & 99 & 1 & 0 & 0 & 1 & 1 & 0 & 0 & 1 & 4 & 38.4 \\
\hline 0015 & 46 & 1 & 1 & 0 & 0 & 1 & 0 & 0 & 0 & 3 & 37.4 \\
\hline 0026 & 144 & 0 & 0 & 0 & 1 & 1 & 1 & 1 & 1 & 5 & 35.4 \\
\hline 0029 & 258 & 0 & 0 & 1 & 0 & 1 & 0 & 1 & 0 & 3 & 33.7 \\
\hline 0010 & 108 & 0 & 0 & 0 & 1 & 1 & 1 & 1 & 0 & 4 & 24.7 \\
\hline 0001 & 119 & 0 & 0 & 0 & 0 & 1 & 1 & 0 & 1 & 3 & 23 \\
\hline 0011 & 142 & 0 & 0 & 0 & 1 & 1 & 1 & 0 & 0 & 3 & 20.7 \\
\hline 0025 & 103 & 0 & 0 & 0 & 0 & 1 & 0 & 1 & 1 & 3 & 18.7 \\
\hline 0006 & 157 & 0 & 0 & 0 & 0 & 1 & 1 & 1 & 0 & 3 & 17.7 \\
\hline 0008 & 98 & 0 & 0 & 0 & 1 & 0 & 0 & 0 & 1 & 2 & 17.7 \\
\hline 0030 & 92 & 0 & 0 & 0 & 0 & 1 & 1 & 1 & 0 & 3 & 17.7 \\
\hline 0034 & 180 & 0 & 0 & 0 & 0 & 1 & 1 & 1 & 0 & 3 & 17.7 \\
\hline 0020 & 112 & 0 & 0 & 0 & 1 & 1 & 0 & 1 & 0 & 3 & 16.4 \\
\hline 0032 & 50 & 0 & 0 & 0 & 0 & 1 & 1 & 0 & 0 & 2 & 13 \\
\hline 0035 & 75 & 0 & 0 & 0 & 1 & 0 & 0 & 1 & 0 & 2 & 12.4 \\
\hline 0024 & 196 & 0 & 0 & 0 & 1 & 1 & 0 & 0 & 0 & 2 & 11.7 \\
\hline 0004 & 100 & 0 & 0 & 0 & 0 & 0 & 0 & 0 & 1 & 1 & 10 \\
\hline 0005 & 205 & 0 & 0 & 0 & 0 & 1 & 0 & 1 & 0 & 2 & 8.7 \\
\hline 0017 & 227 & 0 & 0 & 0 & 0 & 1 & 0 & 1 & 0 & 2 & 8.7 \\
\hline 0022 & 106 & 0 & 0 & 0 & 0 & 1 & 0 & 1 & 0 & 2 & 8.7 \\
\hline 0007 & 296 & 0 & 0 & 0 & 0 & 0 & 0 & 1 & 0 & 1 & 4.7 \\
\hline 0018 & 163 & 0 & 0 & 0 & 0 & 0 & 0 & 1 & 0 & 1 & 4.7 \\
\hline 0033 & 334 & 0 & 0 & 0 & 0 & 0 & 0 & 1 & 0 & 1 & 4.7 \\
\hline 0014 & 48 & 0 & 0 & 0 & 0 & 1 & 0 & 0 & 0 & 1 & 4.0 \\
\hline 0021 & 134 & 0 & 0 & 0 & 0 & 1 & 0 & 0 & 0 & 1 & 4.0 \\
\hline 0002 & 98 & 0 & 0 & 0 & 0 & 0 & 0 & 0 & 0 & 0 & 0.0 \\
\hline 0009 & 72 & 0 & 0 & 0 & 0 & 0 & 0 & 0 & 0 & 0 & 0.0 \\
\hline 0012 & 119 & 0 & 0 & 0 & 0 & 0 & 0 & 0 & 0 & 0 & 0.0 \\
\hline 0013 & 119 & 0 & 0 & 0 & 0 & 0 & 0 & 0 & 0 & 0 & 0.0 \\
\hline 0016 & 394 & 0 & 0 & 0 & 0 & 0 & 0 & 0 & 0 & 0 & 0.0 \\
\hline 0019 & 130 & 0 & 0 & 0 & 0 & 0 & 0 & 0 & 0 & 0 & 0.0 \\
\hline \multicolumn{2}{|c|}{ Total number of facilities } & 6 & 6 & 4 & 13 & 25 & 11 & 21 & 10 & & \\
\hline \multicolumn{2}{|c|}{ Assumed centrality } & 100 & 100 & 100 & 100 & 100 & 100 & 100 & 100 & & \\
\hline \multicolumn{2}{|l|}{ Weight } & 16.7 & 16.7 & 25 & 7.7 & 4 & 9.0 & 4.7 & 10 & & \\
\hline
\end{tabular}

Source: Author's Construct, 2017 
Table 4 Differences in Proportions and Means

\begin{tabular}{|c|c|c|}
\hline \multicolumn{3}{|l|}{ Student Enrolment } \\
\hline Response Variables & $p$-value $(a<0.05)$ & Mean(SD) \\
\hline Functional Toilet Facility & 0.04 & \\
\hline - Exist & & 177(76) \\
\hline - Does not exist & & $123(82)$ \\
\hline Functional HWS* & 0.69 & \\
\hline - Exist & & $165(92)$ \\
\hline \multirow[t]{2}{*}{ - Does not exist } & & 150(81) \\
\hline & Functional HWS & \\
\hline Explanatory Variables & $p$, Fisher's Exact & Cramer's V \\
\hline Functional Water facility & 0.00 & 0.80 \\
\hline Functional Toilet facility & 0.16 & - \\
\hline Financial Provision for WS $^{+}$ & 0.03 & 0.39 \\
\hline \multicolumn{3}{|l|}{ Two-Sample Proportion Test } \\
\hline & $z$ (p-value) & Proportion $(95 \% \mathrm{Cl})$ \\
\hline Functional Water facility & $-4.87(0.00)$ & \\
\hline - Within School & & $0.83(0.54-1.13)$ \\
\hline - Outside School & & $0.03(-0.03-0.10)$ \\
\hline $\begin{array}{l}\text { Financial Provision for } \\
\text { water supply }\end{array}$ & $-2.38(0.02)$ & \\
\hline - Exist & & $0.40(0.10-0.70)$ \\
\hline - Does not exist & & $0.07(-0.02-0.17)$ \\
\hline
\end{tabular}

*HWS-Handwashing station ${ }^{+}$WS-Water supply

number of schools have a functional toilet facility within the schools' premises. In such a situation, students could potentially resort to public toilet facilities, private homes or open defecation. It is however worth noting that the existence of a toilet facility in a school does not automatically guarantee its usage. Factors including facility age, and facility type could influence facility usage [15]. In this study, a simple pit latrine is identified to be the most common toilet facility in participating schools (88\%). This condition obviously raises concern since a pit latrine is an unimproved toilet type, and hence not recommended for a school setting [5].

The availability of soap in schools is crucial to the promotion of school-based handwashing with soap (HWWS). However, it is well understood that the mere availability of soap does not imply the existence of a handwashing station, as additional facilities are required. Though the results show that most schools had soap available, it is also evident that few schools had a functional handwashing station, and therefore the use of soap (which was mostly found in front of offices of teachers) could have been used for other purposes such as washing teachers' dishes after meals. The commonality of soap is consistent with the result of a study conducted in Ghana which showed that $96 \%$ of study settings had soap available, but were used for other purposes apart from handwashing (e.g. washing dishes) [16]; and with another which reported that $83 \%$ of a sample of schools in Ghana had soap available [8]. The result is however in contrast to that of a study conducted in Senegal which reported that only $10 \%$ of participating schools had soap available to students [17].

Furthermore, the situation in which only $19 \%$ of schools had a handwashing facility attached to (or located within the premises) of a toilet facility appears worrisome and inconsistent with existing guidelines for setting up WASH facilities in schools [5]. It is common knowledge that the proximity of a handwashing facility to a toilet facility can potentially influence adherence to HWWS after toilet use.

The situation in which a large number of schools use a shared receptacle for students' handwashing, and a shared cotton towel for students' hand drying leaves much to be desired. In a country where infectious diseases continue to claim many lives, the implications of this practice on cross-infections is a matter of concern. In a recent study conducted in Ghanaian preschools, 8 different bacteria, 2 different parasites and a fungus were observed in water samples collected from a shared receptacle used by school children for handwashing [18].

The gloomy situation described above could potentially be explained in part by the WASH facility deficiency which appears to be characteristic of many schools in the municipality. The result of the scalogram analysis points to a situation where many schools are constrained in terms of basic facilities such as a functional water facility, a functional handwashing station, paper towels, and a financial provision for WASH. An observation of the centrality indices from the scalogram matrix shows that some schools (16\%) have as low as 0.0 index indicating the non-existence of any of the observed WASH facilities. The WASH facility deficiency characterising participating schools is similar to a situation reported in Malawi where only 33\% of handwashing facilities in schools were functional, and no school had soap available for handwashing [19]. An intervention by government and civil society organisations in addressing the situation will be timely.

\section{Differences in proportions of handwashing facilities}

With respect to functional toilet facilities in schools, the mean student enrolment was higher for schools which had this facility when compared with schools which lacked this facility. The higher student enrolment figures observed among schools with a functional toilet facility could suggest the possibility of a facility-driven selection of schools by parents or guardians. However, it is beyond the purview of this present study to draw such conclusions since additional studies may be required to draw a conclusion. The existence of a functional toilet facility 
was however not associated with the existence of a functional handwashing station, which is an issue of concern considering the crucial complementarity of a handwashing station and a toilet facility [5].

Furthermore, a greater proportion of schools which had a functional water facility also had a functional handwashing station. The existence of a functional water facility in a school is crucial to the setting up of a functional handwashing station. Among others, this facilitates the provision of adequate running water which has been identified as key to the practice of proper handwashing with soap $[20,21]$.

Similarly, a greater proportion of schools which had a financial provision for water supply also had a functional handwashing station. To ensure the sustainability of functional handwashing stations in schools, the role of a budgetary allocation is imperative, and the result of this study has shown that a financial provision is essential to the existence of a functional handwashing station in schools. Recognizing the crucial role of a financial provision, it becomes a concern that few schools reported the existence of this scheme (27\%). This result is consistent with that of a study conducted in Nicaragua where 95\% of schools did not have a budgetary allocation for the provision of an essential WASH facility as soap [22].

\section{Limitation}

The generalization of results of this study is limited to settings which have socio-economic characteristics similar to that of the geographic scope of this study.

\section{Conclusion}

The importance of having an enabling environment to enhance the adoption of healthful behaviours is widely known among the health promotion fraternity. Ensuring the existence of adequate hygiene facilities in schools is a good way towards creating an environment which enables the adoption and maintenance of a safe hygiene behaviour among school children. The evidence generated by this study suggests a hygiene facility deficit across a range of schools.

Also, results of this study indicate that there is not enough evidence to accept the two null hypotheses formulated. Thus, schools with a financial provision for water supply tend to have a functional handwashing station. Similarly, schools with a functional water facility within its compound tend to have a functional handwashing station. This implies that concerted efforts by government, educational authorities and civil society organisations towards assisting schools especially in low resource areas to have a sustainable budgetary allocation for WASH facilities will be imperative.

\section{Abbreviations}

CHRPE: Committee on Human ResearchPublication and Ethics; Cl: Centrality Index; HA: Alternative Hypothesis; Ho: Null Hypothesis; HW: Handwashing; HWWS: Handwashing with Soap; M: Mean; SD: Standard Deviation; UNICEF: United Nations Children's Fund; WASH: Water, Sanitation and Hygiene; WinS: WASH in School

\section{Acknowledgements \\ We acknowledge the efforts of researchers and practitioners who have contributed in diverse ways towards building the evidence-base within the field of hand hygiene. \\ Funding \\ The research received financial support from the Danish International Development Agency (DANIDA), and the Kwame Nkrumah University of Science and Technology (KNUST).}

\section{Availability of data and materials}

The datasets used and/or analysed during the current study are available from the corresponding author on reasonable request.

\section{Authors' contributions}

EAB facilitated the process of collecting, analyzing and interpreting research data. MJH provided content and methodological expertise in the design and implementation of the research. SN offered methodological scrutiny in the design of the research. GG initiated the conceptualisation of the research. All authors read and approved the final manuscript.

\section{Ethics approval and consent to participate}

The research was approved by the Committee on Human Research, Publication and Ethics (CHRPE) of the Kwame Nkrumah University of Science and Technology - Ghana. In addition, a written consent was obtained from the Ejisu-Juaben Municipal Education Directorate of the Ghana Education Service, a regulatory body of all basic schools within the study area.

\section{Competing interests}

The authors declare that they have no competing interests.

\section{Publisher's Note}

Springer Nature remains neutral with regard to jurisdictional claims in published maps and institutional affiliations.

\section{Author details}

${ }^{1}$ Department of Health Promotion and Education, Kwame Nkrumah University of Science and Technology (KNUST), Kumasi, Ghana. ${ }^{2}$ Department of Health Promotion and Behavioral Sciences, University of Louisville, Louisville, USA. ${ }^{3}$ Department of Global and International Health, Kwame Nkrumah University of Science and Technology (KNUST), Kumasi, Ghana. ${ }^{4}$ Unit for Health Promotion Research, University of Southern Denmark (SDU), Esbjerg, Denmark.

Received: 8 August 2017 Accepted: 20 April 2018

Published online: 02 May 2018

\section{References}

1. Wang H, Naghavi M, Allen C, Barber R, Bhutta ZA, Carter C, Casey C, Charlson F, Chen C, Coates M, Dandona H. Global, regional, and national life expectancy, all-cause mortality, and cause-specific mortality for 249 causes of death, 1980-2015: a systematic analysis for the global burden of disease study 2015. Lancet. 2016;388(10053):1459-544.

2. UNICEF. One is too many: ending child deaths from pneumonia and diarrhoea. New York: UNICEF Press; 2016.

3. JET G, Tadesse G, Mekete K, Wuletaw Y, Gebretsadik A, French MD, Harrison WE, Drake LJ, Gardiner IA, Yard E, Templeton MR. School water, sanitation, and hygiene, soil-transmitted helminths, and Schistosomes: National Mapping in Ethiopia. PLoS Negl Trop Dis. 2016;10(3):1-21.

4. UNICEF. More than soap and Water: taking handwashing with soap to scale: UNICEF handwashing training module, 2008. (Online) http:// globalhandwashing.org/wp-content/uploads/2015/03/HWWS-More-ThanSoap-and-Water_Training-Module.pdf. 
5. Adams J, Bartram J, Sims J, Chartier Y. Water, sanitation and hygiene standards for schools in low-cost settings. Geneva: WHO/UNICEF; 2009.

6. UNICEF. WASH in schools monitoring package. New York: UNICEF; 2011.

7. Steiner-Asiedu M, Van-Ess S, Papoe M, Setorglo J, Asiedu DK, Anderson AK. Hand washing practices among school children in Ghana. Cur Res J Soc Sci. 2011;3(4):293-300.

8. Monney I, Martinson O, Asampana A, Marfo A. Assessing hand hygiene practices in schools benefiting from the Ghana school feeding Programme. Science Journal of Public Health. 2014;2(1):7-14.

9. Yamane T. Statistics: an introductory analysis. 2nd ed. New York: Harper and Row; 1967.

10. Pennsylvania State University. Probability theory and mathematical statistics, 2016. (Online): https://onlinecourses.science.psu.edu/stat414/node/264. (2016.5.11).

11. Bowling A. Research methods in health: investigating health and health sciences. 3rd ed. Berkshire: McGraw-Hill Company; 2009.

12. StratTrek. Sample size: stratified random samples, 2016. (Online) http:// stattrek.com/sample-size/stratified-sample.aspx (2016.9.25)

13. Moore GT, Sugiyama T, O'Donnel L. Children's physical environments rating scale. Sydney: University of Sydney; 2003.

14. UNICEF. Advancing WASH in schools monitoring: working paper. New York: UNICEF Press; 2015

15. Garn JV, Caruso BA, Drews-Botsch CD, Kramer MR, Brumback BA, Rheingans $R D$, Freeman MC. Factors associated with pupil toilet use in Kenyan primary schools. Int J Environ Res Publ Health. 2014;11(9):9694-711.

16. Scott B, Curtis V, Rabie T, Garbrah-aidoo N. Health in our hands, but not in our heads : understanding hygiene motivation in Ghana. Health Policy Plann. 2007:44(22):225-33.

17. Sidibe M, Curtis V. Can hygiene be cool and fun? Insights from school children in Senegal. London: London School of Hygiene and Tropical Medicine; 2007.

18. Tetteh-Quarcoo PB, Anim-Baidoo I, Attah SK, Abdul-Latif Baako B, Opintan JA, Minamor AA, Abdul-Rahman M, Ayeh-Kumi PF. Microbial content of 'bowl water' used for communal handwashing in preschools within Accra metropolis. Ghana Int J Microbiol. 2016;2016:8-10.

19. Save the Children. Improving water, sanitation, and hygiene behaviors in schools: successes and lessons learned from Mangochi District, Malawi, 2008. (Online) https://www.ircwash.org/blog/hygiene-promotion-lessonssave-childrens-programme-malawi. (2018.1.23).

20. Centers for Disease Control and Prevention. Handwashing: clean hands saves life, 2015. (Online) http://www.cdc.gov/handwashing/when-howhandwashing.html. (2016.8.31).

21. WHO. How to handwash. 2009. (Online) http://www.who.int/gpsc/5may/ How_To_HandWash_Poster.pdf. (2016.8.31).

22. Jordanova T, Cronk R, Obando W, Medina OZ, Kinoshita R, Bartram J. Water, sanitation, and hygiene in schools in low socio-economic regions in Nicaragua: a cross-sectional survey. Int J Environ Res Publ Health. 2015;12(6): 6197-217.

Ready to submit your research? Choose BMC and benefit from:

- fast, convenient online submission

- thorough peer review by experienced researchers in your field

- rapid publication on acceptance

- support for research data, including large and complex data types

- gold Open Access which fosters wider collaboration and increased citations

- maximum visibility for your research: over $100 \mathrm{M}$ website views per year

At BMC, research is always in progress.

Learn more biomedcentral.com/submissions 